\title{
不同情景模式下雄安新区的水资源 利用效率和节水潜力分析
}

\author{
赵志博 ${ }^{1}$, 赵领娣 ${ }^{1,2}$, 王亚薇 ${ }^{1}$, 袁 田 $^{1}$ \\ (1. 中国海洋大学经济学院, 青岛 $266100 ; 2$. 教育部人文社会科学重点研究基地, \\ 中国海洋大学海洋发展研究院,青岛 266100)
}

\begin{abstract}
摘要：雄安新区是千年大计、国家大事, 水资源短缺与水体污染成为制约其发展的主要问题。 从水资源利用效率及节水潜力视角出发, 以深圳发展历程为标杆, 结合情景分析与方向性距离 函数等模型, 展示到 2035 年不同情景的雄安水资源利用效率及节水潜力发展图景和路径。研究 表明: 从利用效率看, 在基准、起步、建成情景下雄安呈现出由低效率区到较高效率区再到高效 率区的变化态势。从节水潜力看, 效率改善空间减小、技术落差比增加等表明雄安节水潜力得 到充分挖掘。杜绝污水直排、积极发展污水处理技术、优化新区产业结构等是促使水资源利用 效率提高的有效手段,是雄安实现绿色生态发展的重要保障。
\end{abstract}

关键词: 水资源利用效率;节水潜力;情景分析法;方向性距离函数;雄安新区

自 2017 年 4 月 1 日以习近平同志为核心的党中央提出设立河北雄安新区这一重大历 史性战略选择后，2018年4月《河北雄安新区规划纲要》横空出世，对高起点规划、高 标准建设雄安新区提供了根本遵循。这是继深圳经济特区和上海浦东新区之后的又一项 历史性工程, 是千年大计、国家大事。雄安新区包括河北省雄县、容城县、安新县及其周 边 29 个乡镇, 处在一个以北京为顶点, 以京广、京津两条轴线为两翼的扇形三角展开地 带 ${ }^{[1]}$, 是带动河北省经济发展的增长极, 同时也是疏解北京非首都功能的集中承载地 ${ }^{[2]}$, 未来将成为 “牛鼻子” 推动京津冀协同发展。

雄安新区未来的发展不仅是党和政府所关心的重大问题, 也是摆在学者面前一个值 得深度思考的研究议题。诚然, 学者们已经对雄安新区的现状和未来进行了一定程度的 探讨，但通过文献梳理，发现已有文献关注的焦点主要集中于战略发展解读 ${ }^{[-2]}$ 、生态问 题分析 ${ }^{[3-4]}$ 、资源概况现状描述等方面 ${ }^{[5-6]}$ 。冊庸置疑, 这些研究为深人理解雄安新区的发 展提供了非常有益的见解, 但尚未有从水资源利用效率及节水潜力角度的定量研究。雄 安新区位于海河流域, 海河流域存在严重水资源短缺、地下水超采等问题 ${ }^{[3]}$ 。深人分析雄 安新区的水资源现状，发现其单位人均水资源拥有量为 $1167.11 \mathrm{~m}^{3}$ ，低于全国单位人均 水资源拥有量的 $1956.96 \mathrm{~m}^{3[4]}$ 。白洋淀作为雄安新区主要的淡水来源, 存在着水旱以及水 资源污染等问题 ${ }^{[-6]}$ 。从古至今, 水资源几乎与所有的人类活动密切相关，在农业灌溉、 工业生产、生态稳定、居民生活等方面发挥着重要作用 ${ }^{[7]}$ 。而目前水资源短缺和水资源分

收稿日期: 2019-05-12; 修订日期：2019-09-20

基金项目：国家自然科学基金项目（71473233）

作者简介: 赵志博 (1992-), 女, 河北唐山人, 博士研究生, 研究方向为自然资源与环境经济。

E-mail: zhibozhao0728@163.com

通讯作者：赵领娣（1963-)，女，河南武陟人，博士，教授，博士生导师，研究方向为资源环境与可持续发展。

E-mail: lingdizhao512@163.com 
配不均也制约着我国可持续发展 ${ }^{[8-10]}$ 。因此, 以白洋淀为依托的雄安新区的未来建设和发 展，同样离不开水资源这一基础性的自然资源和战略性的经济资源，水资源可持续利用 将是影响其顺利发展的关键因素。雄安新区只有提高水资源的利用效率并挖掘其节水潜 力, 才能从根本上应对水资源短缺与水体污染的资源环境问题, 实现水城共融、绿色生 态发展的战略目标 ${ }^{[1-12]}$ 。

根据雄安新区的发展要求，逐步设定水资源利用的不同情景，可以为雄安未来发展 提供重要决策参考。简单地假设新区用水总量、人口规模、污水排放量等不变显然是不 妥当的，考虑雄安新区发展的可能性变化是应有的做法，而情景分析恰恰是一种立足现 状，通过改变有关因素以实现对未来趋势判断的常用方法。目前学者已将此方法应用到 各个领域, 如, Shaikh 等 ${ }^{[13]}$ 选取土耳其电力行业, 对水足迹、碳足迹进行测算, 并结合 情景分析法，估计了基础情景、官方政府计划情景、可再生能源重点发展情景下的电力 生产部门用水量、取水量以及碳排放量的变化趋势; Duan 等 ${ }^{[14]}$ 采用 Granger 因果分析法 验证了北京经济部门能源与水资源利用存在着单向因果关系，并根据当前国家的水和能 源政策，采用情景分析法探讨不同管理建议的影响效果; $\mathrm{Wu}$ 等 ${ }^{[15}$ 提出了代表矿井突水演 化的 12 个场景要素，建立了基于 $\mathrm{BNs}$ 的矿井突水风险评价框架，并结合情景分析法，提 出了相应的灾难响应机制。

综上所述，水资源不仅仅是雄安新区建设的基础，更是新区绿色生态发展的关键。 本文有别于雄安战略发展解读、资源概况描述等已有研究，创新性地从水资源利用效率 及节水潜力视角出发, 运用情景预测法（Scenario Prediction）、共同前沿与组前沿模型 (Metafrontier and Groupfrontier)、方向性距离函数法（Directional Distance Function，DDF） 以及自然断点法（Natural Breaks Classification Method），对雄安新区水资源利用效率和 节水潜力进行多情景动态分析。以深圳发展历程为标杆，根据《河北雄安新区规划纲 要》的发展要求逐步设定雄安未来可能的用水总量、人口规模、污水排放量等因素。本 文将雄安自设立至 2035年的建设目标划分为基准情景（Business as Usual，BAU)、起步 情景（Starting Process，SP）、建成情景（Construction Completion，CC）。这不仅丰富了 关于新区的学术研究, 而且为雄安提供水资源利用效率提高和节水潜力提升的发展路 径, 增强雄安新区未来发展时水资源的可持续性，从而为《河北雄安新区规划纲要》以 及十九大报告中提出的高起点规划、高标准建设雄安新区目标的实现提供借鉴。

\section{1 研究方法与数据来源}

\section{1 模型建立与指标选择}

\section{1 .1 共同前沿与组前沿模型}

雄安新区所处的京津冀地带位于我国东部地区, 其经济发展速度与中部和西部地区 有着显著差异。DEA 假定所有决策单元都是同质的，当测量效率或者生产率时忽略了组 间异质性，这会导致所测结果有偏差性 ${ }^{[1]]}$ 。因此，本文将雄安新区与全国 287 个城市划分 为东、中、西三大组别，探讨共同前沿与组前沿下的水资源利用效率是必要且合理的。 共同前沿指的是所有决策单元都具有相同的潜在技术水平，组前沿是由具有同质性的决 策单元构成的前沿面，组前沿与共同前沿的差别在于所参考的技术集不一样 ${ }^{[17-18]}$, 示意图 如图 1 所示。 
假设 $k(k=1,2, \cdots, K)$ 个决策单元，每个单元在 $t(t=$ $1,2, \cdots, T)$ 时期投入集合为 $x=\left(x_{1}^{t}, x_{2}^{t}, x_{3}^{t}, \cdots, x_{N}^{t}\right), x \in R_{+}^{N}$, 期望产出集合为 $y=\left(y_{1}^{t}, y_{2}^{t}, y_{3}^{t}, \cdots, y_{M}^{t}\right), y \in R_{+}^{M}$, 非期望产 出集合为 $b=\left(b_{1}^{t}, b_{2}^{t}, b_{3}^{t}, \cdots, b_{I}^{t}\right), b \in R_{+}^{I}$, 其共同前沿生产 可能性集合为 $P(x)=\{(y, b): x$ 能够生产 $(y, b)\}$, 组前沿为 共同前沿下具有同质性的集合划分, 组前沿与共同前沿 的关系为 $P(x)=P^{1}(x) \bigcup P^{2}(x) \bigcup P^{3}(x) \bigcup, \cdots, \bigcup P^{k}(x)$ 。

共同前沿下的效率（Meta Technology Efficiency， MTE) 可以分解为组前沿下的效率 (Group Technology Efficiency, GTE) 和技术落差比（Meta Technology Ratio，MTR)，三者关系如式（1）。技术落差比测度了共 同前沿与组前沿下的效率差异，其值越大表示共同前沿

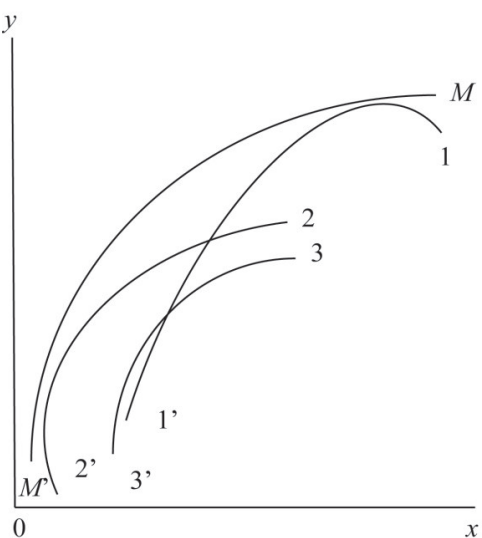

图 1 共同前沿与组前沿

Fig. 1 The metafrontier and the groupfrontier 下的技术与组前沿下的技术越接近，其值越小表示组前沿与共同前沿的技术差距较大 ${ }^{[19]}$ 。

$$
\operatorname{MTR}^{k}(x, y, b)=\frac{\operatorname{MTE}(x, y, b)}{\operatorname{GTE}^{k}(x, y, b)}
$$

\subsection{2 方向性距离函数模型}

合理测度水资源利用效率是水资源可持续利用的重要前提，忽略水污染等非期望产 出测算的水资源利用效率是不准确和非全面的 ${ }^{[20]}$ 。因此, 深人定量地分析涵盖污水排放 的水资源利用效率显得尤为重要。通常对非期望产出的处理大致分为三种：第一种是将 非期望产出视为投人变量 ; 第二种是采用倒数处置法将非期望产出视为期望产出, 但这 两种方法具有局限性，不符合生产过程，并不具有经济意义 ${ }^{[21-22]}$; 第三种方法为方向性距 离函数, 它克服了传统 Shephard产出导向距离函数的缺陷, 测度了给定方向、投人和给 定环境技术水平下期望产出扩大和非期望产出缩小的可能性大小 ${ }^{[23-25]}$ 。所以，本文采用产 出导向型方向性距离函数模型，将非期望产出视为弱可处置与零结合性、期望产出强可 处置，纳人共同的生产集，进行水资源利用效率评价 ${ }^{[23]}$ 。数学表达如下:

$$
\vec{D}_{o}(x, y, b ; g)=\sup \{\beta:(y, b)+\beta g \in P(x)\}
$$

式中: $g$ 为方向性矩阵, 在本文中 $g_{k^{\prime}}^{t}=\left(y_{k^{t}}^{t},-b_{k^{\prime}}^{t}\right)$ 表示期望产出的增加和非期望产出的减 少, 产出导向型方向性距离函数的线性规划表达式如下:

$$
\begin{aligned}
& \vec{D}_{o}\left(x^{t, k^{\prime}}, y^{t, k^{\prime}}, b^{t, k^{\prime}} ; y^{t, k^{\prime}},-b^{t, k^{\prime}}\right)=\max \beta \\
& \text { s.t. } \sum_{k=1}^{K} z_{k} y_{k m}^{t} \geqslant(1+\beta) y_{k^{\prime} \times m}^{t}, m=1, \cdots, M \\
& \sum_{k=1}^{K} z_{k} b_{k i}^{t}=(1-\beta) b_{k^{\prime} \times i}^{t}, i=1, \cdots, I, \\
& \sum_{k=1}^{K} z_{k} x_{k n}^{t} \leqslant(1-\beta) x_{k^{\prime} \times n}^{t}, n=1, \cdots, N, \\
& z_{k} \geqslant 0, k=1, \cdots, K
\end{aligned}
$$

产出导向型方向性距离函数所求得的水资源利用效率关系式如下 ${ }^{[23]}$ :

$$
\theta=1 /\left[1+\vec{D}_{o}(x, y, b ; y, b)\right]
$$

式中： $\theta$ 为水资源利用效率值。 


\section{1 .3 自然断点法}

自然断点法（Natural Breaks Classification Method）是地理学研究中经典的统计分析 工具，用于呈现和识别数据在区域空间上的分异特征 ${ }^{[26]}$ 。自然断点法选择间断点的依据 为通过反复调整区域边界，测算组内方差与组间方差，寻找使得组内方差最小，组间方 差最大的间断点, 实现数据集合的分级聚类。

\subsection{4 指标选择}

根据《河北雄安新区规划纲要》, 雄安新区包括容城县、安新县、雄县三个行政辖区 及其周围一些乡镇, 作为北京非首都功能疏解集中承载地, 其未来要打造成推动高质量 发展的全国样板，成为高水平的社会主义现代化城市。因此，为把雄安打造成水资源利 用效率最优的全国样板城市，本文将雄安新区与全国 287 个城市的水资源利用情况对 比，以此发现雄安新区水资源利用效率现状的提升空间，进而达到水资源可持续利用的 目的。鉴于县级数据的可得性，采用 2015 年数据代替雄安目前的水资源利用情况，每个 决策单元选取各地区生产总值、污水年排放总量作为期望产出与非期望产出，选取固定 资产投资、人口规模、用水总量作为投人指标，指标选择说明具体如下:

(1) 期望产出指标一一地区生产总值 $(G D P)$ 。水资源作为一种要素投人生产时能够 带动经济的增长, 主要体现为地区生产总值的增加。因此本文用地区生产总值表示各个 地方的期望产出。数据来源于《中国城市统计年鉴》和《中国县域统计年鉴》。

（2）非期望产出指标——污水年排放总量（Sewage）。污水排放不仅仅是利用水资源 进行经济生产时的附属品, 也是未来雄安新区依托的白洋淀的主要污染源之一, 因此本 文将污水年排放总量作为直接反映测算水资源利用效率时非期望产出的衡量指标。数据 来源于《中国城市建设统计年鉴》和《城镇排水统计年鉴》。

（3）固定资产投资（Capital）。雄安新区及其他决策单元的发展必须依赖资本投人来 拉动经济增长, 因此固定资产投资是一不可忽视的重要指标。数据来源于《中国城市统 计年鉴》和《中国县域统计年鉴》。

（4）人口规模（Population）。雄安新区及其他决策单元在未来发展过程中，会大批 量引进高端人才, 实现人口规模的集聚, 进而增加用水需求, 因此人口规模的变化是影 响水资源利用效率的一项重要指标，本文将人口规模纳人指标体系，该变量均采用年末 常住人口数据，不区分户籍。数据来源于《中国统计年鉴》和《中国县域统计年鉴》。

（5）用水总量（Consumption）。水资源利用效率的相关研究中，一般选取用水总量 作为水资源消耗量, 它衡量了某一地区用水量的变化情况, 该变量包括生产运营用水、 公共服务用水、居民家庭用水和其他用水四个方面。数据来源于《中国县城建设统计年 鉴》和《中国城市建设统计年鉴》。

其中雄安新区与全国 287 个城市 2015 年各个指标的描述性统计如表 1 所示:

表 1 投入产出变量描述性统计

Table 1 Descriptive statistics of input and output variables

\begin{tabular}{llcccc}
\hline 变量 & 单位 & 均值 & 标准差 & 最小值 & 最大值 \\
\hline Capital & 百万元 & 180352.2381 & 179348.1044 & 9005.6100 & 1536796.9000 \\
Population & 万人 & 130.1857 & 236.6863 & 14.1000 & 2415.2700 \\
Consumption & 万 $\mathrm{m}^{3}$ & 16746.0664 & 32040.2727 & 481.4000 & 312224.4200 \\
GDP & 千万元 & 24683.2569 & 32634.8452 & 659.6530 & 251234.5000 \\
Sewage & 万 $\mathrm{m}^{3}$ & 13886.3611 & 25700.9046 & 348.0000 & 230423.0000 \\
\hline
\end{tabular}




\section{2 情景设计与参数构建}

雄安新区在承接北京转移产业的同时，将配置高新高端产业，以有力带动京津冀地 区协同发展。《河北雄安新区规划纲要》指出, 到 2035 年, 雄安新区基本建成绿色低碳、 信息智能、宜居宜业、具有较强竞争力和影响力、人与自然和谐共生的高水平社会主义 现代化城市。在政府政策扶持、人才迅速集聚的背景下，雄安新区的各个方面均会得到 快速发展，仅仅研究现阶段雄安三县的水资源利用效率是不科学的，应以动态发展的思 路对待雄安新区未来的发展。因此本文采用情景分析方法, 考虑到雄安新区规划建设的 指导思想、功能定位、建设目标等因素，将其2035 年发展目标划分为三种情景：基准情 景、起步情景、建成情景，并对不同情景下的水资源效率及节水潜力进行动态分析。

\subsection{1 情景设计}

雄安新区的设立与发展由习近平总书记亲自谋划、决策与推动，得到中共中央以及 全国上下的大力支持，力争发展为推动经济高质量发展的全国样板，成为河北要素净流 人区, 为世界级城市群建设奠定基础。根据《河北雄安新区规划纲要》, 雄安新区是继深 圳经济特区和上海浦东新区之后又一全国意义的特区。

自 1978 年中国实施改革开放，作为四个经济特区之一的深圳经过 38 年的发展，不仅 创造了 “深圳奇迹”，更进一步成为引领时代发展的标杆。深圳之所以能够取得如此瞩目 的成就，得益于政策扶持、人才聚集、技术创新等。就政策而言，深圳通过降低关税、 所得税等优惠政策，吸引了来自全国以及国外的大量投资，进而拉动中国经济快速发 展。就人才与技术而言, 深圳经历了由低技能劳动到高技能劳动的转变, 同样也经历了 以“三来一补” 为特征的简单技术引进到以技术创新为核心的科技型经济特区的转型, 吸引了全国上下的众多人才与大量技术，人才集聚与科技力量成为拉动经济增长的核心 因素，确保深圳的经济总量一直保持在全国前列，成就了“深圳奇迹”与 “时代引领 者”。雄安新区的设立是千年大计、国家大事, 将是党中央汇聚举国之力积极建设的新 区，在土地、财税、金融等方面给予政策支持，确保疏解的人才与产业在雄安得以健康 发展。统筹安排各类转移支付资金、加大地方政府长期债务、实行多层次住房供给政 策、开展金融创新与金融试点工作等措施，巩固新区建设的资金来源与政策保障，支持 力度远高于深圳。就人才与科技而言，雄安不再经历低技能劳动的过渡，而是在短期内 引进大量高素质、高技能人才，实现人才的迅速集聚，与此同时引进节能环保、生物医 药、信息技术等高新高科技产业，打造创新驱动发展引领区，坚持把创新作为雄安质量 发展的第一动力, 进而实现以创新为根本动力的发展。由此可见，雄安所拥有的政策扶 持、人才集聚、科技创新的外部环境与深圳具有惊人相似之处，雄安新区必将发展成为 引领中国经济高质量发展的样板。因此, 以深圳的发展经验规划雄安新区的未来发展具 有一定的标杆性与现实可行性。本文预测其首先会经历五年的建设期，然后经过一定时 期的发展达到 2035 年的建设目标 ${ }^{1}$ 。在雄安原有的发展基础上，分别以 2023 年、2035年 为时间节点对雄安新区的相关指标进行预测，并对水资源利用效率及节水潜力进行动态 分析。本文设置了基准情景、起步情景、建成情景等三种情景，具体说明如表 2 所示。

与此同时，除雄安新区外，全国 287 个城市的投人产出变量也要以一定的增速发

(1) 参考深圳的发展历程，“六五”时期地区生产总值、固定资产投资等年均增长率最大，“七五”时期、“八 五” 时期次之，其余时期变化较为平缓，因此本文据此预测雄安先经历五年起步期，然后经历一定时期的发展达到 2035 年的建设目标。 
表 2 雄安新区不同情景的设定与比较

Table 2 Comparison of Xiong'an New Area under different scenarios

\begin{tabular}{|c|c|c|}
\hline 情景名称 & 情景定义 & 发展展望 \\
\hline 基准情景（BAU） & 以 2015 年为基准年, 分析水资源利用现状 & 以 2015 年的基础数据进行分析 \\
\hline 起步情景（SP） & 将2018-2023 年定义为起步情景 & $\begin{array}{l}\text { 借鉴深圳设立初期的关键指标“预测雄安新区起 } \\
\text { 步情景发展 }\end{array}$ \\
\hline 建成情景（CC） & 将2023-2035 年定义为建成情景 & $\begin{array}{l}\text { 借鉴深圳发展历程中关键指标“预测雄安新区建 } \\
\text { 成情景发展 }\end{array}$ \\
\hline
\end{tabular}

注: “指深圳人均用水量、人均污水排放量、固定资产投资等经济指标。

展。自“十二五” 时期以来，中国经济发展进人 “新常态”，摒弃单纯追求高速度转而走 向高质量发展之路。鉴于此本文设定，在起步情境、建成情景下其余决策单元的投人要 素、产出要素均按照2011-2015 年五年的年均增长率进行增长。

\subsection{2 参数构建}

尽管 2017 年雄安新区的水资源利用状况在现实中已经发生，但限于县级数据的可得 性，目前尚无法对其具体指标进行准确估算。因此，只能结合官方已经公布的相关文件 和数据对雄安目前的状况估计推算。基准情景下, 采用 2015 年的相关数据, 将雄安新区 与全国 287 个城市作为决策单元纳人模型进行水资源利用效率对比分析。接下来对起步 情景和建成情景下的各个指标进行合理预测。

\section{(1) 人口规模}

为有序承接部分在京行政事业单位、总部企业、金融机构、科研院所、在京高校和 医院，未来雄安将实现世界眼光和国际标准人才的聚集，构造多元化的人口结构。结合 《河北雄安新区规划纲要》中的土地规划, 新区起步情景面积约为 $200 \mathrm{~km}^{2}$, 建成情景面 积为 $1770 \mathrm{~km}^{2}$, 按照人口密度小于等于 10000 人 $/ \mathrm{km}^{2}$ 的标准, 人口规模在起步情景下和建 成情景下分别为 200 万、 1770 万。因此综合考虑人口集聚效应、人口密度、土地使用面 积，本文设定起步情境下雄安新区人口规模达到 200 万，建成情景下雄安新区人口达到 1770 万，公式如下：

$$
\begin{aligned}
& \text { Population }_{S P}=\text { Area }_{S P} \times \text { Population density } \\
& \text { Population }_{C C}=\text { Area }_{C C} \times \text { Population density }^{\text {Population }}
\end{aligned}
$$

式中：Population P $_{S P}$ Population $_{C C}$ 代表起步情景和建成情景的人口规模；Area $a_{S P}$ Area $a_{C C}$ 代 表起步情景和建成情景的土地面积; Population density代表《河北雄安新区规划纲要》 中的人口密度。

（2）地区生产总值与固定资产投资

深圳自设立之初经历了“六五” “七五” “八五”“九五”“十五”“十一五”“十二 五” 等 7 个五年规划时期，其中人均 $G D P$ 在各个时期下的年均增长率分别为 $25.1 \%$ 、 $2.6 \% 、 9.5 \% 、 6.2 \% 、 11.8 \% 、 8.4 \% 、 7.8 \%$ ，固定资产投资额在各个时期下的年均增长率 分别为 $89 \%$ 、 $13.3 \% 、 34.6 \% 、 17.6 \% 、 13.8 \% 、 10.5 \% 、 11.1 \%$ 。“六五” 时期深圳实现了 从无到有的飞速发展，呈现出人均 GDP 和固定资产投资额的快速增长。1980年深圳设立 之初的地区生产总值为 27012 万元，经济基础薄弱，仅为雄安设立时地区生产总值的 $1.27 \%$ ，所以按照深圳 “六五” 时期人均 GDP 年均增长率 $25.1 \%$ 以及固定资产投资额年均 增长率 $89 \%$ 的发展速度来模拟雄安新区的发展是不现实的。“七五” “八五” “九五” “十 
一五” 时期深圳人均 $G D P$ 增长速度过慢，较低的增长速度不适合雄安新区打造世界级城 市群的增长需求。“八五” “九五” 时期深圳固定资产投资额的迅猛增长是以城镇化过快 发展为背景的，忽略了人与自然的和谐相处。过高的固定资产投资将带来大量热钱，阻 碍新区实施生态优先、绿色发展的建设理念, 且中国未来经济发展处于结构转型期, 设 立过高的增长可能会在一定程度上走以前的重数量、轻质量的老路, 不利于雄安打造高 质量发展的全国样板。因此，保持必要的、合理的、科学的、相对稳健的发展，选择一 个相对适中的并且与中国未来经济稳健发展目标相一致的增长速度, 不仅符合雄安绿色 生态发展的建设要求，而且契合中国未来经济转型发展的总体基调。

起步情景下，鉴于雄安新区目前仍未进行全面建设，且新区开发强度较低，需要五 年的起步期加强基础设施等的建设，使得新区初具规模，因此人均 $G D P$ 和固定资产投资 额的增长速度不能太慢。新区旨在打造世界级城市群, 踊跃顺应经济全球化的浪潮, 积 极坚持开放的发展道路，力争融人 “一带一路” 建设大潮。“十五” 时期是中国抓住开放 机遇、加人世贸组织、寻求更大发展空间的一个典型时期，所以深圳 “十五” 时期的发 展与雄安新区起步情景下的发展是更为贴切和吻合的，因此借鉴深圳 “十五” 时期的发 展速度来规划雄安新区起步情景的发展，预测起步情景中雄安新区地区生产总值和固定 资产投资的增长率分别为 $11.8 \% 、 13.8 \%$ ，如式 (7)、式 (8)。

建成情景下, 新区坚持生态优先、绿色发展的建设理念, 不会以牺牲环境为代价追 求经济高速发展。“十二五”期间中国经济发展进人新常态，放缓经济发展速度，追求经 济发展质量，将绿色发展放在突出位置。所以在此背景下，将深圳“十二五” 时期的发 展速度作为新区建成情景下的发展依据符合雄安建成期的发展理念。因此参照 “十二 五” 期间的深圳发展速度，预测建成情景下雄安新区的人均 GDP 年均增长率为 $7.8 \%$, 固 定资产投资年均增长率为 $11.1 \%$ ，如式 $(9)$ 、式 $(10)$ 。

$$
\begin{gathered}
G D P_{S P}=G D P_{a v e} \times\left(1+\alpha_{1}\right)^{5} \times \text { Population }_{S P} \\
\text { Capital }_{S P}=\text { Caputal }_{B A U} \times\left(1+\lambda_{1}\right)^{5} \\
G D P_{C C}=G D P_{\text {ave }} \times\left(1+\alpha_{1}\right)^{5} \times\left(1+\alpha_{2}\right)^{12} \times \text { Population }_{C C} \\
\text { Capital }_{C C}=\text { Caputal }_{B A U} \times\left(1+\lambda_{1}\right)^{5} \times\left(1+\lambda_{2}\right)^{12}
\end{gathered}
$$

式中: $G D P_{a v e}$ 为雄安新区基准情景下的人均地区生产总值; $G D P_{S P} 、 G D P_{c c}$ 分别为起步情 景、建成情景下的地区生产总值（图 2)； $\alpha_{1} 、 \alpha_{2}$ 为深圳 “十五” 时期、“十二五” 时期的 人均 $G D P$ 年均增长率; Population ${ }_{S P}$ 、 Population $_{C C}$ 分别为雄安新区起步情景、 建成情景下的人口规模; Capital ${ }_{B A U}$ 、 Capital $_{S P} 、$ Capital $_{C C}$ 为雄安新区基准情 景、起步情景、建成情景下的固定资产 投资额； $\lambda_{1} 、 \lambda_{2}$ 为深圳 “十五” 时期、“十 二五” 时期的固定资产投资年均增长率。

（3）用水总量和污水年排放总量

鉴于人均用水量、人均污水年排放 量存在刚性约束, 不可能出现太大的变 化, 但是考虑到雄安新区的设立是千年

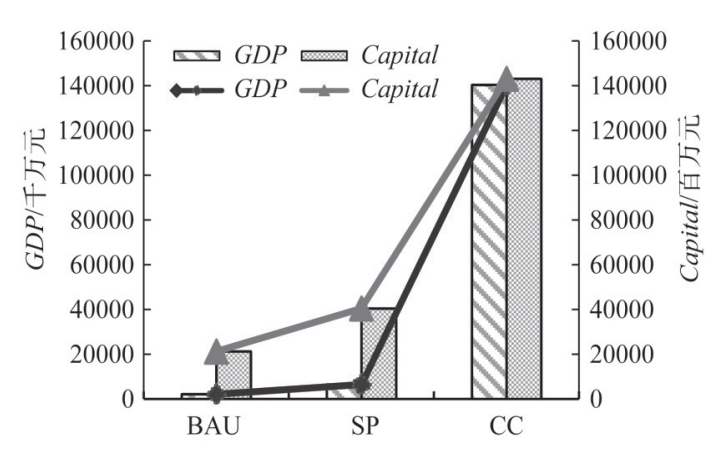

图 2 雄安新区固定资产投资、地区生产总值变动趋势

Fig. 2 The trend of fixed asset investment and regional GDP in Xiong'an New Area 
大计、国家大事，新区设立之初便是高起点、高标准，因此在政策支持、资金筹措、技 术引进等方面会给予最好的配置, 且白洋淀水资源短缺、水污染是制约雄安发展的关键 因素。在这样的背景约束下, 加上雄安建设本身的目标要求, 必须在人均用水量、人均 污水年排放量这两个方面进行控制，否则雄安新区无法得以健康发展。“十二五”时期， 深圳积极响应习总书记的号召, 倡导质量发展, 在新时代背景下调整发展模式。通过数 据分析发现，深圳2011-2015 年的人均用水量、人均污水排放量都呈现出明显下降趋势, 表明节水、污水处理等技术有了较大程度的提高, 因此以深圳发展历程为标杆的雄安也 会达到人均用水量、人均污水年排放量下降的目标。《河北雄安新区规划纲要》明确指 出，要实现白洋淀生态修复，应坚持流域 “控源一截污一治河” 系统治理。因此雄安新 区在发展过程中要严格控制污水排放，提高水资源利用效率。本文以基准情景下的用水 总量和污水年排放量为基数，参照深圳2011-2015年的平均人均用水量的变化率、平均人 均污水排放量的变化率，乘以雄安在起步情境下 200 万的人口设定，对雄安新区起步情 景下的用水总量、污水年排放总量进行调整，如式 (11)、式 (12)。

建成情景下，分别使用深圳2011-2015 年的平均人均用水量的变化率、平均人均污水 排放量的变化率乘以雄安在建成情境下 1770 万的人口设定，对雄安新区 2035 年的用水总 量、污水年排放总量进行合理预测，如式 (13)、式 (14)。

$$
\begin{aligned}
\text { Cpnsumption }_{S P} & =\text { Consumption }_{\text {ave }} \times(1+\gamma)^{5} \times \text { Population }_{S P} \\
\text { Sewage }_{S P} & =\text { Sewage }_{\text {ave }} \times(1+\delta)^{5} \times \text { Population }_{S P} \\
\text { Consumption }_{C C} & =\text { Consumption }_{\text {ave }} \times(1+\gamma)^{17} \times \text { Population }_{C C} \\
\text { Sewage }_{C C} & =\text { Sewage }_{\text {ave }} \times(1+\delta)^{17} \times \text { Population }_{C C}
\end{aligned}
$$

式中: Consumption ave 雄安新区基准情景下的人均用水量; Consumption ${ }_{S P}$. Consumption $_{C C}$ 分别为起步情景、建成情景下的用水总量 (图 3); $\gamma$ 为深圳 2011-2015 年的平均人均 用水量的变化率; Population $S$ 、Population $C C$ 分别为雄安新区起步情景、建成情景下的人 口规模; Sewage ave 雄安新区基准情景下的人均污水年排放量；Sewage SP $_{\text {P Sewage }}$ 分别 为雄安新区起步情景、建成情景下的污水 年排放总量； $\delta$ 为深圳2011-2015 年的平均 人均污水排放量的变化率。

\section{2 结果分析}

\section{1 水资源利用效率动态多情景分析}

由于篇幅限制，对各个情景下的投人 产出指标不再一一列出。根据以上情景设 定，基于处理非期望产出的方向性距离函 数模型, 依据线性规划 (3), 采用软件 Matlab R 2013 a 测算 288 个决策单元在不 同情景下的水资源利用效率，然后采用软

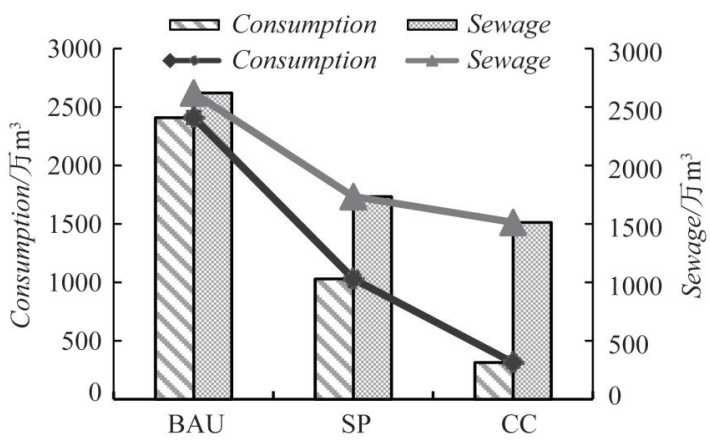

图 3 雄安新区用水总量、污水排放量变动趋势

Fig. 3 The trend of total water and total sewage discharge in Xiong'an New Area 件 ArcGIS 10.3 对 288 个决策单元的效率值进行自然断点分析。由于决策单元数量过多, 只列出各个省会的水资源利用效率值以及自然断点分层结果，如表 3 所示。 
表 3 基准、起步、建成情景下雄安新区与各省省会水资源利用效率值及自然断点分区

Table 3 Water resources utilization efficiency value and natural breaks classifications of Xiong'an

New Area and capitals under the BAU, SP and CC scenarios

\begin{tabular}{|c|c|c|c|c|c|c|}
\hline \multirow{2}{*}{ 城市（区） } & \multicolumn{2}{|c|}{ 基准情景 } & \multicolumn{2}{|c|}{ 起步情景 } & \multicolumn{2}{|c|}{ 建成情景 } \\
\hline & 效率值 & 自然断点分区 & 效率值 & 自然断点分区 & 效率值 & 自然断点分区 \\
\hline 北京 & 0.9791 & IV & 0.9643 & $\mathrm{~V}$ & 0.7114 & III \\
\hline 天津 & 0.7740 & II & 0.6795 & II & 0.6185 & II \\
\hline 石家庄 & 0.7078 & I & 0.6580 & II & 0.6012 & I \\
\hline 太原 & 0.7144 & II & 0.6111 & I & 0.5615 & I \\
\hline 呼和浩特 & 0.8579 & III & 0.8192 & IV & 0.7360 & III \\
\hline 沈阳 & 0.7543 & II & 0.9994 & V & 0.6259 & II \\
\hline 长春 & 0.7362 & II & 0.6504 & II & 0.6059 & II \\
\hline 哈尔滨 & 0.7447 & II & 0.6552 & II & 0.6085 & II \\
\hline 上海 & 0.8791 & III & 0.8868 & IV & 0.6056 & II \\
\hline 南京 & 0.7609 & II & 0.8923 & IV & 0.8361 & IV \\
\hline 杭州 & 0.8110 & III & 0.6984 & III & 0.6026 & I \\
\hline 合肥 & 0.7030 & I & 0.6451 & II & 0.5904 & I \\
\hline 福州 & 0.9926 & V & 0.6836 & II & 0.6086 & II \\
\hline 南昌 & 0.6862 & I & 0.6199 & I & 0.5719 & I \\
\hline 济南 & 0.8136 & III & 0.7065 & III & 0.6401 & II \\
\hline 郑州 & 0.9522 & IV & 0.9812 & V & 0.6211 & II \\
\hline 武汉 & 0.9731 & IV & 0.9722 & V & 0.7081 & III \\
\hline 长沙 & 0.7647 & II & 0.9510 & V & 0.7008 & III \\
\hline 广州 & 0.9945 & V & 0.9022 & IV & 0.6231 & II \\
\hline 南宁 & 0.6673 & I & 0.6291 & II & 0.5764 & I \\
\hline 海口 & 0.6635 & I & 0.7628 & III & 1.0000 & $\mathrm{~V}$ \\
\hline 重庆 & 0.6925 & I & 0.6147 & I & 0.5834 & I \\
\hline 成都 & 0.9732 & IV & 0.9680 & V & 0.6850 & III \\
\hline 贵阳 & 0.6808 & I & 1.0000 & V & 1.0000 & $\mathrm{~V}$ \\
\hline 昆明 & 0.7399 & II & 0.7295 & III & 0.6012 & I \\
\hline 西安 & 0.7562 & II & 0.7197 & III & 0.6274 & II \\
\hline 兰州 & 0.6880 & I & 0.6436 & II & 0.5991 & I \\
\hline 西宁 & 0.6525 & I & 0.5731 & I & 0.5567 & I \\
\hline 银川 & 0.9897 & V & 0.6038 & I & 0.5673 & I \\
\hline 乌鲁木齐 & 0.7368 & II & 0.8921 & IV & 1.0000 & $\mathrm{~V}$ \\
\hline 雄安 & 0.6869 & I & 0.8347 & IV & 1.0000 & V \\
\hline
\end{tabular}

注：I、II、III、IV、V 分别表示按自然断点法划分的低效率区、较低效率区、中效率区、较高效率区、高效率区。

本文采用自然断点法将雄安新区以及全国 287 个城市的水资源利用效率数值划分为 五类（低效率区、较低效率区、中效率区、较高效率区、高效率区）进行空间分异格局 分析。

总体来看，中国水资源利用效率空间分异格局较为明显，中效率区以上的城市大部 分集中于东部（北京、上海、杭州、济南等）、中部地区（武汉、长沙、成都等），且北 
京、呼和浩特、武汉、成都等城市的水资源利用效率值都处于中效率区及以上。其他决策 单元的水资源利用效率在不同情景下呈现出明显的差异，仍有一定的技术改善空间。雄 安的效率值呈现出缓慢上升的趋势，基准情景下位于低效率区，起步情景下位于较高效 率区，建成情景中达到高效率区。这种上升趋势是因为雄安新区自设立之初就高度重视 水资源的利用效率，加强对水资源的使用管理，严格把控人口规模以及地区生产总值等的 增长速度，从而为 2035 年清新明亮、水城共融的建设目标的实现奠定良好的基础 ${ }^{[2]}$ 。

从单一情景看, 基准情景描述的是雄安新区的水资源利用现状, 效率值为 0.6869 , 离有效技术前沿有一定的距离, 属于低效率区。所以雄安新区要想成为绿色生态发展新 城，应付出更大的努力，提高对水资源利用的重视程度。深人分析水资源利用效率偏低 的原因，淀区周围造纸、有色金属冶炼等高污染高能耗企业将大量未处理的污水直接排 人白洋淀，导致新区最大的淡水资源白洋淀存在水污染等问题 ${ }^{[3]}$ 。可见新区的污水排放方 式一直较为粗放, 污水处理技术水平较低, 是制约雄安发展的关键因素。此外, 基准情 景里雄安新区与天津、石家庄、太原、重庆等城市的水资源利用效率偏差较小，通过发 展污水处理技术很有希望超过这些城市。起步情景描述的是雄安新区通过五年的发展即 到 2023 年的情景, 雄安新区的水资源利用效率位于较高效率区, 呈现出缓慢上升的趋 势。在建设初期，新区倡导质量发展，加大污染治理，实施退耕还淀，建立多水源补水 机制, 保证水资源的供给 ${ }^{[27]}$ 。不仅如此, 根据《河北雄安新区规划》的发展要求, 新区 在起步情景里摒弃传统的高污染高耗能企业和项目，采用清洁生产技术，进而严格控制 污水排放总量。此外通过节水技术、水循环技术的大力提升，导致人均用水总量缓慢下 降、人均污水排放量增速放缓、最终呈现出水资源利用效率上升的现象。通过一段时期 的建设, 雄安新区已经基本达到 2035 年的建设目标, 即建成情景里所描述的情况。在建 成情景里, 雄安新区的水资源利用效率一直处于高效率区, 这是由于雄安新区通过起步 期的建设，并没有放松对水资源可持续利用的关注，继续严格把握雄安新区的建设目 标，积极建设绿色智慧新城，通过引进现代服务业以及信息技术等高端高新产业，推进 产业转型升级，减少用水需求，合理控制人口规模以及进一步提高污水处理技术，从而 确保雄安新区水资源利用效率一直保持在最优水平。

\section{2 水资源节水潜力动态多情景分析}

本文采用共同前沿与组前沿模型计算不同情景下东、中、西三大组别的效率值以及 技术落差比，结果如表4所示。

由东、中、西三个组别的组内效率来看，整体上雄安新区的水资源利用效率呈缓慢 上升趋势, 表明其一直在努力追赶含有非期望产出的最优技术前沿。基准情景下, 雄安 新区的效率值为 0.5789 , 低于东部地区的效率均值 0.8164 , 差距为 0.2375 ; 起步情景 下, 其效率值为 0.6536 , 与东部地区效率均值的差距缩小为 0.1562 ; 建成情景中, 雄安 新区的水资源利用效率达到最优前沿面, 远远高于东部地区的组内效率均值 0.8464 , 表 明雄安新区的技术水平逐渐提升, 节水潜力较大。因此在建设过程中, 雄安只要高度重 视合理分配水资源，大力发展节水技术、控制人口规模、加大污水治理力度，就会实现 水资源效率提升的目标。

就共同前沿下水资源利用效率的均值而言，东部地区在不同情景下的效率均值分别 为 $0.6729 、 0.6733 、 0.7064$, 存在 $32.71 \% 、 32.67 \% 、 29.36 \%$ 的效率改善空间。雄安新区 在不同情景下的效率分别为 $0.5586 、 0.6270 、 1.0000$ ，即采用潜在的最优生产技术，新区 
表 4 不同情景、不同组别的效率值以及技术落差比

Table 4 Efficiency values and metatechnology ratios for different scenarios and different groups

\begin{tabular}{|c|c|c|c|c|c|c|}
\hline \multirow{2}{*}{ 组别 } & \multicolumn{2}{|c|}{ GTE } & \multicolumn{2}{|c|}{ MTE } & \multicolumn{2}{|c|}{ MTR } \\
\hline & 均值 & 标准差 & 均值 & 标准差 & 均值 & 标准差 \\
\hline 东部一基准情景 & 0.8164 & 0.1101 & 0.6729 & 0.0707 & 0.8319 & 0.0850 \\
\hline 东部一起步情景 & 0.8098 & 0.1204 & 0.6733 & 0.0893 & 0.8414 & 0.1122 \\
\hline 东部一建成情景 & 0.8468 & 0.1560 & 0.7064 & 0.1370 & 0.8468 & 0.1364 \\
\hline 中部一基准情景 & 0.7971 & 0.1152 & 0.6488 & 0.0512 & 0.8243 & 0.0882 \\
\hline 中部一起步情景 & 0.7926 & 0.1309 & 0.6434 & 0.0593 & 0.8236 & 0.0816 \\
\hline 中部一建成情景 & 0.8684 & 0.1495 & 0.6848 & 0.1158 & 0.8013 & 0.1244 \\
\hline 西部一基准情景 & 0.6708 & 0.0863 & 0.6598 & 0.0757 & 0.9855 & 0.0284 \\
\hline 西部一起步情景 & 0.7086 & 0.1448 & 0.6670 & 0.0946 & 0.9555 & 0.0911 \\
\hline 西部一建成情景 & 0.7491 & 0.1662 & 0.7175 & 0.1495 & 0.9697 & 0.1253 \\
\hline 东部整体 & 0.8243 & 0.1313 & 0.6842 & 0.1041 & 0.8400 & 0.1133 \\
\hline 中部整体 & 0.8194 & 0.1371 & 0.6590 & 0.0828 & 0.8164 & 0.1004 \\
\hline 西部整体 & 0.7095 & 0.1404 & 0.6814 & 0.1140 & 0.9702 & 0.0918 \\
\hline 雄安一基准情景 & 0.5789 & & 0.5586 & & 0.9649 & \\
\hline 雄安一起步情景 & 0.6536 & & 0.6270 & & 0.9593 & \\
\hline 雄安一建成情景 & 1.0000 & & 1.0000 & & 1.0000 & \\
\hline
\end{tabular}

在基准、起步、建成情景下将存在 $44.14 \% 、 37.30 \% 、 0$ 的效率改善空间。可见基准情景 下雄安的改善空间大于东部整体，在起步情景里发生显著性减小，建成情景里直接达到 最优水平。效率改善空间的减小表明雄安关于水资源利用的技术水平在逐渐提高，拥有 可观的节水潜力。因此, 只要雄安新区提高水资源利用效率的关注程度, 注重发展节水 技术，控制污水排放，这一改善空间差距有望减少直到为零。

由东、中、西三个组别的技术落差比来看，整体上雄安新区各个情景下的技术落差 比都高于对应情景下的东部地区。在基准情景下雄安新区的技术落差比值为 0.9649 , 其 达到共同前沿水资源利用技术的 $96.49 \%$ ，表明雄安新区的技术水平几乎达到组内共同前 沿的最优技术水平。与基准情景相比，建成情景下技术落差比缓慢爬升，对最优前沿的 技术利用率逐渐增加，达到 100\%。虽然起步情景下的技术落差比稍低于基准情景，但差 距不大，有望回归最优技术水平。

综上所述, 雄安新区在未来的发展过程中, 水资源节水潜力较大, 有望实现《河北 雄安新区规划纲要》的绿色生态发展的建设目标。

\section{3 结论与讨论}

自以习近平同志为核心的党中央提出构建雄安新区的重大决策部署以来，其发展与 定位便受到学者们的广泛讨论。因此本文结合《河北雄安新区规划纲要》, 以深圳发展历 程为标杆, 将雄安新区 2035 年的建设目标划分为基准、起步、建成等三个情景, 结合处 理非期望产出的方向性距离函数模型、情景分析法、共同前沿与组前沿模型以及自然断 点法, 以固定资产投资、人口规模、用水总量作为生产过程中的投人变量, 以期望产出 地区生产总值、非期望产出污水年排放总量作为生产过程中的产出变量，对雄安新区的 
水资源利用效率及节水潜力进行多情景动态分析。研究表明：

（1）基准情景下，新区的效率值为 0.6869 ，位于低效率区，其效率改善空间为 $44.14 \%$ ，技术落差比为 0.9649 。由于白洋淀周围造纸、有色金属冶炼等高污染高能耗企 业将大量未处理的污水直接排人白洋淀，致使新区污水排放量增加，在基准情景下，粗 放的污水排放方式、较低的污水处理技术是新区水资源利用效率偏低的重要原因。

（2）起步情景下，其效率值显著提升，达到 0.8347 ，处于较高效率区，且雄安的效 率改善空间减小至 $37.30 \%$ ，技术落差比为 0.9593 ，离有效前沿的距离逐渐减小。基于技 术外溢的短期有效性，在五年的起步发展时期，摒弃高污染高耗能企业，吸收和借鉴先 进污水处理技术，是促使新区水资源利用效率上升的关键因素。

（3）建成情景下，效率值爬升至 $1 ，$ 位于高效率区，且新区效率改善空间减小至 0 , 技术落差比增加至 1 , 达到最优技术前沿。鉴于产业结构调整的缓慢性和长期性，在十 二年的发展过程中，调整新区产业布局，推进产业转型升级，促使资源投人向集约化转 型，是确保水资源利用效率保持在最优水平的核心原因。

基于上述结论，提出以下建议：第一，鉴于基准情景下雄安水资源利用效率较低的 测算结果及可能原因，应坚决杜绝污水直排。转变粗放式的水资源利用模式，引导社会 提高节水意识，树立污水处理观念是杜绝污水直排的有效手段。第二，针对起步情景下 新区水资源利用效率提升且节水潜力得到部分释放的测算结果及可能原因，应积极推进 污水处理技术。加大科技投人，引进和培养科技人才，借鉴和吸收国际先进污水处理技 术，是确保新区对最优技术的有效使用和推广的有效措施。第三，基于建成情景下雄安 新区水资源利用效率达到最优且节水潜力得到充分挖掘的测算结果及可能原因，应优化 新区产业结构。大力引进信息技术产业、高端现代服务业等高端高新产业，有序建设人 工智能、前沿信息技术等示范性重点项目，是优化雄安产业结构的重要举措。

\section{参考文献(References):}

１］周民良. 唱衰雄安新区论调为什么站不住脚. 人民论坛, 2017, (12): 40-42. [ZHOU M L. Why the mouthing argument of Xiong'an New Area is untenable. People's Tribune, 2017, (12): 40-42.]

[2] 叶中华,魏玉君. 雄安新区承接人口疏解的策略分析: 基于首尔和东京的经验. 当代经济管理, 2017, 39(12): 39-46. [YE Z H, WEI Y J. Strategy analysis of population dispersal in Xiong'an New district: Based on the experiences of Seoul and Tokyo. Contemporary Economic Management, 2017, 39(12): 39-46.]

[3] 夏军, 张永勇. 雄安新区建设水安全保障面临的问题与挑战. 中国科学院院刊, 2017, 32(11): 1199-1205. [XIA J, ZHANG Y Y. Water resource and pollution safeguard for Xiong'an New Area construction and its sustainable develop. Bulletin of Chinese Academy of Sciences, 2017, 32(11): 1199-1205.]

[4] 王树强, 徐娜. 雄安新区生态环境承载力综合评价. 经济与管理研究, 2017, 38(11): 31-38. [WANG S Q, XU N. Comprehensive evaluation of eco-environmental carrying capacity in Xiong'an New Area. Research on Economics and Management, 2017, 38(11): 31-38.]

[5] 匡文慧, 杨天荣, 颜凤芹. 河北雄安新区建设的区域地表本底特征与生态管控. 地理学报, 2017, 72(6): 947-959. [KUANG W H, YANG T R, YAN F Q. Regional urban land-cover characteristics and ecological regulation during the construction of Xiong'an New District, Hebei province, China. Acta Geographica Sinica, 2017, 72(6): 947-959.]

[6] 姜鲁光, 吕佩忆, 封志明, 等. 雄安新区土地利用空间特征及起步区方案比选研究. 资源科学, 2017, 39(6): 991-998. [JIANG L G, LYU P Y, FENG Z M, et al. Land use patterns of the Xiong'an New Area and comparison among potential choices of start zone. Resources Science, 2017, 39(6): 991-998.]

[7] BROWN C M, LUND J R, CAI X, et al. The future of water resources systems analysis: Toward a scientific framework for sustainable water management. Water Resources Research, 2015, 51(8): 6110-6124. 
[8] 孙才志, 姜坤, 赵良仕. 中国水资源绿色效率测度及空间格局研究. 自然资源学报, 2017, 32(12): 1999-2011. [SUN C Z, JIANG K, ZHAO L S. Measurement of green efficiency of water utilization and its spatial pattern in China. Journal of Natural Resources, 2017, 32(12): 1999-2011.]

[9] CHEN W, WU S, LEI Y, et al. China's water footprint by province, and inter-provincial transfer of virtual water. Ecological Indicators, 2017, 74: 321-333.

[10] 周迪, 周丰年. 中国水资源利用效率俱乐部趋同的检验、测度及解释: 2003-2015 年. 自然资源学报, 2018, 33(7): 1103-1115. [ZHOU D, ZHOU F N. Inspection, measurement and interpretation of club convergence of water resources utilization efficiency in China: 2003-2015. Journal of Natural Resources, 2018, 33(7): 1103-1115.]

[11] PAN Z, WANG Y, JIN J, et al. Set pair analysis method for coordination evaluation in water resources utilizing conflict. Physics and Chemistry of the Earth, Parts A/B/C, 2017, 101: 149-156.

[12] SUN Y, LIU N, SHANG J, et al. Sustainable utilization of water resources in China: A system dynamics model. Journal of Cleaner Production, 2017, 142: 613-625.

[13] SHAIKH M A, KUCUKVAR M, ONAT N C, et al. A framework for water and carbon footprint analysis of national electricity production scenarios. Energy, 2017, 139: 406-421.

[14] DUAN C, CHEN B. Energy-water nexus in Beijing: Causality analysis and scenario analysis. Energy Procedia, 2017, 105: 3966-3971.

[15] WU J, XU S, ZHOU R, et al. Scenario analysis of mine water inrush hazard using Bayesian networks. Safety Science, 2016, 89: 231-239.

[16] OH D H. A metafrontier approach for measuring an environmentally sensitive productivity growth index. Energy Economics, 2010, 32(1): 146-157.

[17] BATTESE G E, RAO D S P. Technology gap, efficiency, and a stochastic metafrontier function. International Journal of Business and Economics, 2002, 1(2): 87-93.

[18] BATTESE G E, RAO D S P, O'DONNELL C J. A metafrontier production function for estimation of technical efficiencies and technology gaps for firms operating under different technologies. Journal of Productivity Analysis, 2004, 21(1): 91-103.

[19] O'DONNELL C J, RAO D S P, BATTESE G E. Metafrontier frameworks for the study of firm-level efficiencies and technology ratios. Empirical Economics, 2008, 34(2): 231-255.

[20] 丁绪辉, 贺菊花, 王柳元. 考虑非合意产出的省际水资源利用效率及驱动因素研究: 基于 SE-SBM 与 Tobit模型的考 察. 中国人口・资源与环境, 2018, 28(1): 157-164. [DING X H, HE J H, WANG L Y. Inter-provincial water resources utilization efficiency and its driving factors considering undesirable outputs: Based on SE-SBM and Tobit model. China Population, Resources and Environment, 2018, 28(1): 157-164.]

[21] HAILU A. Nonparametric productivity analysis with undesirable outputs: Reply. American Journal of Agricultural Economics, 2003, 85(4): 1075-1077.

[22] 周国兰, 季凯文, 甘永春, 等. 环境管制背景下鄱阳湖生态经济区新型工业化效率研究. 江西财经大学学报, 2012, (5): 71-79. [ZHOU G L, JI K W, GAN Y C, et al. A study of new industrialization efficiency of Poyang Lake ecological economic zone in the context of environmental control. Journal of Jiangxi University of Finance and Economics, 2012, (5): 71-79.]

[23] CHUNG Y H, FARE R, GROSSKOPF S. Productivity and undesirable outputs: A directional distance function approach. Journal of Environment Management, 1997, 51(3): 229-240.

[24] SHEPHERD R W. Theory of Cost and Production Functions. Princeton: Princeton University Press, 1970.

[25] FARE R, GROSSKOPF S, PASURKA JR C A. Environmental production functions and environmental directional distance functions. Energy, 2007, 32(7): 1055-1066

[26] JENKS G F. The data model concept in statistical mapping. International Yearbook of Cartography, 1967, 7: 186-190.

[27] 中共中央国务院关于对《河北雄安新区规划纲要》的批复. 人民日报, 2018-04-21(001). [CPC Central Committee and State Council's reply to the "Planning Outline for Hebei Xiong'an New Area". People's Daily, 2018-04-21(001).] 


\title{
Analysis of water resources utilization efficiency and water saving potential in Xiong'an New Area under different scenarios
}

\author{
ZHAO Zhi-bo ${ }^{1}$, ZHAO Ling-di ${ }^{1,2}$, WANG Ya-wei ${ }^{1}$, YUAN Tian ${ }^{1}$ \\ (1. School of Economics, Ocean University of China, Qingdao 266100, Shandong, China; 2. Institute of \\ Marine Development of OUC, Key Research Institute of Humanities and Social Sciences at \\ Universities, Ministry of Education, Qingdao 266100, Shandong, China)
}

\begin{abstract}
Xiong'an New Area is a millennium plan and a national event. Water shortage and water pollution have become the main problems which restrict its development. Different from the existing research on Xiong'an strategic development interpretation and resource profile description, this paper combines with scenario analysis and directional distance function models so as to show the water resources utilization efficiency and water saving potential development landscape and path of different scenarios in 2035 for the first time and it is innovatively based on the development of Shenzhen. The research shows that Xiong'an presents a change from low-efficiency zone to high-efficiency zone to high-efficiency zone in the Business as Usual, Starting Process and Construction Completion scenarios from the perspective of utilization efficiency. From the perspective of water saving potential, the reduction of efficiency improvement space and the increase in metatechnology ratios indicate that water saving potential of Xiong'an has been fully explored. Avoiding direct sewage discharge, developing sewage treatment technology actively and optimizing the industrial structure of the Xiong'an New Area are effective ways to promote the utilization efficiency of water resources, which is also an important guarantee for Xiong'an to realize green ecological development.
\end{abstract}

Keywords: water resources utilization efficiency; water saving potential; scenario analysis method; directional distance function; Xiong'an New Area 